\title{
Task Assignments and Incentives: Generalists versus Specialists*
}

\author{
Suraj Prasad ${ }^{\dagger}$
}

January 17, 2009

\begin{abstract}
I develop an agency model of job assignments where jobs differ based on the breadth of tasks. A tradeoff between task complementarities and relative abilities of workers results in those with balanced skills being assigned to multi-task jobs. The same tradeoff between complementarities and relative abilities also influences incentives to sort privately informed workers to jobs. I then draw on a variety of sources (survey data, case studies, and anecdotal evidence) to suggest that relative abilities and multi-tasking play an important role in managerial assignments of non-academic research scientists.
\end{abstract}

${ }^{*}$ I would like to thank two anonymous referees, Jennifer Reinganum (the editor), as well as Gaetano Antinolfi, Edward Greenberg, Stephanie Lau, Glenn MacDonald, Kieron Meagher, Charles Moul, John Nachbar, Hideo Owan, Bruce Petersen, Bill Schworm, Randy Silvers and Michael Waldman for helpful comments. Thanks go to Barton Hamilton for suggesting the data set and for his helpful comments. I also thank seminar participants at the Universities of Adelaide, Deakin, Melbourne, NSW, and Sydney, and conference participants at International Industrial Organization Conference (2007), North American Summer Meetings of the Econometric Society (2007), and European Association for Research in Industrial Economics (2008). I am also grateful for financial support from the Australian School of Business. Finally, thanks go to Maurya Green, Nirmala Kannankutty, Adrian McQueen and Florin Petrescu for their help with the SDR data set. The use of NSF data does not imply NSF endorsement of the research methods or conclusions contained in the article. All errors are my own.

${ }^{\dagger}$ School of Economics, University of New South Wales. s.prasad@unsw.edu.au 


\section{Introduction}

Economists typically think of job assignments within organizations as hierarchical (Calvo and Wellisz (1979), Rosen (1982), Waldman (1984)). These articles build on two key assumptions. First, jobs are similar in the skills they require. Second, jobs differ based on rank and authority; there are productivity spillovers from higher level managerial jobs to lower level jobs. Taken together, these assumptions imply that the most "able" workers are assigned to higher level managerial positions.

These assumptions of similar skills and different rank are reasonable in many settings. As an example, compare the job of a division head with that of a chief executive officer (CEO) in an organization. Both jobs require similar skills: the ability to make quick decisions and the ability to implement these decisions at a lower level. The only difference is in terms of rank. Being higher up in a hierarchy, a CEO can influence the productivity of all divisions below. Thus it makes sense for the most able worker in an organization to be made the CEO.

But there are other contexts where these assumptions appear less valid. Managing a research lab requires different skills from doing one's own research. Similarly, the best academic researchers in a university need not make the best deans. And finally, a successful lawyer who brings in many clients need not make the best manager in a law firm. This article suggests a complementary approach to hierarchy theories to address these specific examples: task breadth. Some workers are assigned to broad jobs (lab managers, deans, and managers of law firms) whereas others are assigned to narrow jobs (non-academic researchers, academic researchers, and legal specialists). This approach, in contrast to hierarchy theories, allows for jobs to differ based on skills and shifts the emphasis from authority to the portfolio of tasks that a worker performs. Using this framework of task breadth, I study how workers are assigned to different jobs and how compensation schemes sort them.

To examine the assignment problem, I use a two-task principal agent model based on MacDonald and Marx (2001), with a risk neutral principal and a continuum of risk averse agents. In the model, agents have a unit of time that they have to allocate across two tasks. Outcomes on tasks are 
stochastically related to the time spent on them in a very simple way; the probability of success on a task equals the time allocated to it and these probabilities are independent across tasks. Two elements are critical to the analysis. The first is that tasks are complementary for a given agent. Complementarities ensure that some agents in the model are assigned to broad jobs. Second, agents differ in their relative abilities which are modeled through their cost functions. Agents who have a relative advantage in one task are called specialists whereas agents who are equally able at several tasks are called generalists. Differences in relative abilities introduce worker heterogeneity in the model and increase the benefits of specialized jobs. The interaction between complementarities and relative abilities determines task assignments and the design of incentives.

The model is split into two parts. The first part considers a case of full information and studies assignments in this setting. The main result here is that balance plays an important role in assignments. Generalists get assigned to multi-task jobs, whereas specialists are assigned more to the task that they are good at. When applied to the assignment of research scientists to managerial positions, this result says that relative rather than absolute abilities are important. This implication is different from hierarchy theories and is testable.

The second part of the model considers a case where agents have private information about their time allocation and abilities and studies both assignments and optimal sorting contracts. The key result here is that optimal contracts pay more in the event of full and no success and less in the event of partial success to sort privately informed agents. Because this makes the tasks complementary in terms of an agents preferences, I refer to this property as incentive complementarities. Incentive complementarities align the interests of the principal and a specialist by making it more costly for a specialist to choose a multi-task job. However, generalists bear more risk which they have to be compensated for. This result provides an interesting way to differentiate compensation across jobs. In terms of the examples above, the pay of a research manager should be high only when outcomes move together, even when this involves failure at all tasks. This prevents individuals who are strong only on the research dimension from choosing these jobs. 
Because the model in this article builds on the framework of MacDonald and Marx (2001) it is useful to highlight the main points of departure. MacDonald and Marx (2001) consider a setting with complementary tasks and symmetric specialists. They show that complementarities help in solving a moral hazard problem. My article differs in two ways. First, my focus is on asymmetric types where agents differ in their relative abilities and second I allow for gains from specialization by setting a positive payoff from the partial success outcome. Both of these assumptions give my article a completely different focus from MacDonald and Marx (2001). The asymmetry introduces worker heterogeneity based on relative abilities and together with the payoff structure leads to both narrow and broad job assignments. The asymmetry also shifts the incentive problem from an effort allocation one (this is what MacDonald and Marx (2001) study) to a sorting problem. Incentive complementarities have a sorting role in my article rather than a time allocation one.

To see more clearly how this article departs from the previous literature on job assignments it is useful to apply the theory to managerial assignments in research organizations. Consider a research organization with two tasks, research and supervision. The research task requires scientific knowledge and technical skills whereas supervision requires the ability to make quick decisions and good social and communication skills. Hold supervisory skills fixed. Hierarchical theories (Calvo and Wellisz (1979), Rosen (1982), Waldman (1984), Murphy (1986), Garicano and Rossi-Hansberg (2006)) suggest that those with higher research skills should be assigned to the supervision task only (because they are more able overall) whereas the multi-task perspective in this model suggests that those with lower research skills (because relative abilities matter) should be assigned to a mix (because of complementarities) of research and supervisory tasks.

I draw on two main sources of evidence to suggest that relative abilities and multi-tasking play an important role in managerial assignments in research organizations. The first source of evidence is based on the Survey of Doctorate Recipients (SDR) over the years 2001 to 2003. This data set surveys scientists and engineers with doctoral degrees in the United Sates. I focus on a group of non-academic scientists who only do research and then track their activities over a period of 
time. Some scientists continue to specialize in research whereas others switch to a combination of research and supervisory tasks. Using patent and publication productivity as a proxy for research ability and the number of workers directly supervised as a proxy for supervisory ability, I find the following results. First, holding supervisory ability fixed, researchers with a higher number of patents continue to specialize in research whereas researchers with a lower number of patents combine research with the supervision task. Second, restricting my attention to individuals who were granted patents, I find that those who publish articles in refereed journals and work in research oriented firms are less likely to switch to management.

I supplement the SDR analysis above with other sources of evidence. These include case studies, examples from business newspapers, reports from human resource consultants, and interviews with human resource and technical personnel. Using these sources, I examine the notion of "dual career tracks" where some technical workers stay on in a technical career and others move into management. I suggest that a primary objective of dual career tracks is to assign workers based on their relative abilities and that this is especially true for top scientists in an organization.

There are other articles that examine job assignments and incentives in a multi-task setting (Holmstrom and Milgrom (1991), Itoh (1994)) . The crucial feature that differentiates my article from the two mentioned above is that agents are heterogeneous in my framework. Lindbeck and Snower (2000) develop a model to show how informational and technological complementarities have led to modern work practices such as job rotation and multi-tasking. Once again, they do not study how job assignments vary with worker heterogeneity. Lazear (2005a) develops a theory of entrepreneurship and shows that individuals with balanced skills are more likely to become entrepreneurs. My article shows that balance should play an important role in any setting where tasks are complementary, not just in the case of entrepreneurship. Another idea that is related to this article is that of task specific human capital (Gibbons and Waldman (2004)). Their idea would suggest that managers perform some research related tasks to utilize the human capital that they acquired from doing research earlier. Finally, there are theories of job assignments where the 
comparative advantage of workers plays an important role (Sattinger (1975), Rosen (1978)). The primary focus of these articles, however, is to explain why earnings distributions are positively skewed rather than to explain patterns of assignments observed in organizations. Furthermore, in these articles jobs differ based on specialized tasks rather than task breadth.

This article is also related to work on organizational design and incentives. Hart and Moore (2005) consider the allocation of decision rights amongst identical agents and show that coordinators (those who combine several assets or alternatively those who multi-task) should be senior to specialists in a hierarchy. ${ }^{1}$ Thus, they provide a foundation for viewing management as a multi-task job. Lazear (2005b) and Lazear (2000) show how organizations design incentives to attract a more able pool of workers where ability is modeled as a single dimensional variable. Finally, this article adds to a well established theory of incentives in organizations. ${ }^{2}$ The main departure from these theories is that workers are assumed to be heterogenous here.

Another approach to hierarchical assignments is one where workers abilities are measured by the information they can process (Prat (1997), Geanakoplos and Milgrom (1991)). A more recent article by Ferreira and Sah (2007) takes a different approach by focussing on a tradeoff between information processing and communication costs. Specialists can process information in one area but cannot communicate with specialists in other areas. Generalists on the other hand cannot process information in any area but can communicate with specialists. They go on to show that when information from various specialists is valuable, generalists are allocated decision making authority. Their article is similar to mine in the distinction they make between generalists and specialists. The difference though, is in the approach taken. My main objective is to suggest a new way to classify jobs based on multi-tasking whereas their focus is to study the tradeoff between specialization and communication costs. Also they do not examine compensation and incentive

\footnotetext{
${ }^{1}$ Also see Becker and Murphy (1992) and Harris and Raviv (2002) for a tradeoff between specialization and coordination.

${ }^{2}$ The benchmark models of agency theory (Holmstrom (1979) and Grossman and Hart (1983)) show that tying pay to a noisy signal of effort involves a tradeoff between insurance and incentives. Subsequent articles examine the problem of inducing effort in settings with multiple tasks (Holmstrom and Milgrom (1991), Baker (1992)), multiple agents (Lazear and Rosen (1981), Holmstrom and Milgrom (1987)) or both (Itoh (1994)).
} 
issues at all.

\section{Model}

I build on a model by MacDonald and Marx $(2001)^{3}$ with a risk neutral principal and a continuum of risk averse agents. There are two tasks with each task having two outcomes, 0 and 1 , where 0 denotes failure and 1 denotes success. Each agent is endowed with one unit of time which he splits across two tasks. The probability of success for each task is equal to the time that an agent puts into that particular task and these probabilities are independent across tasks. The principal gets a benefit of $Q_{h}$ if both tasks are successful, a benefit of $Q_{l}<Q_{h}$ if only one task is successful, and 0 if no task is successful.

There are three types of agents who are differentiated based on their abilities across tasks. These abilities are modeled through an agent's cost function. An agent who is less able incurs a higher effort cost for any given time $t$ spent on the task. The first type is a specialist in task 1 and his cost function is given by $\phi_{s 1}\left(t_{s 1}\right)=\alpha_{s} t_{s 1}+\beta_{s}\left(1-t_{s 1}\right)$ with $\alpha_{s}<\beta_{s}$, where $t_{s 1}$ is the time that this agent spends at task 1 . Likewise, a specialist at task 2 has a cost function given by $\phi_{s 2}\left(t_{s 2}\right)=\alpha_{s} t_{s 2}+\beta_{s}\left(1-t_{s 2}\right)$ where $t_{s 2}$ is the time that this agent spends at task 2 . Let $\alpha_{s}=\alpha$ and $\beta_{s}=\beta$. As both types of specialists are symmetric, I use the subscript $s$ to denote either specialist when it does not cause any confusion. Finally the third type has a cost function given by $\phi_{g}\left(t_{g}\right)=\alpha_{g} t_{g}+\beta_{g}\left(1-t_{g}\right)$ with $\alpha_{g}=\beta_{g}=1$. I call this type a generalist. Let $q_{g}$ denote the fraction of agents who are generalists and $q_{s j}$ denote the fraction of agents who are specialists at task $j$. For simplicity, I assume that half the agents are generalists and the remaining half are split equally into specialists of either task.

Contracts specify a reward for each possible outcome. A contract is given by the vector $\left(f_{i}, p_{1 i}, p_{2 i}, n_{i}\right)$ where $f$ denotes the payment to an agent in the event of full success, $p_{1}$ denotes the payment for success only on task $1, p_{2}$ denotes the payment for success only on task $2, n$ denotes

\footnotetext{
${ }^{3}$ Also see Bardsley (2001) for a similar framework.
} 
the payment for no success and the subscript $i$ denotes the type of the agent.

The following table summarizes the various outcomes, their associated probabilities, benefits to the principal and contracts.

\begin{tabular}{|c|c|c|c|c|}
\hline Outcomes & $(1,1)$ & $(1,0)$ & $(0,1)$ & $(0,0)$ \\
\hline Probabilities & $t(1-t)$ & $t^{2}$ & $(1-t)^{2}$ & $t(1-t)$ \\
\hline Benefits & $Q_{h}$ & $Q_{l}$ & $Q_{l}$ & 0 \\
\hline Contracts & $f_{i}$ & $p_{1 i}$ & $p_{2 i}$ & $n_{i}$ \\
\hline
\end{tabular}

Agents are risk averse and maximize expected utility. Type $i^{\prime} s$ expected utility given a contract and his time allocation is given by

$$
V_{i}\left(f_{i}, p_{1 i}, p_{2 i}, n_{i} ; t_{i}\right)=t_{i}\left(1-t_{i}\right)\left(u\left(f_{i}\right)+u\left(n_{i}\right)\right)+t_{i}^{2} u\left(p_{1 i}\right)+\left(1-t_{i}\right)^{2} u\left(p_{2 i}\right)-\phi_{i}\left(t_{i}\right)
$$

where $u$ is strictly increasing, strictly concave and twice continuously differentiable. All types of agents have a reservation utility denoted by $u_{0}$. The principal's expected profit is given by

$$
\pi\left(f_{i}, p_{1 i}, p_{2 i}, n_{i} ; t_{i}\right)=\sum_{i} q_{i}\left(R\left(t_{i}\right)-C_{i}\left(f_{i}, p_{1 i}, p_{2 i}, n_{i} ; t_{i}\right)\right)
$$

where the revenue for type $i$ is given by $R\left(t_{i}\right)=t_{i}\left(1-t_{i}\right) Q_{h}+\left(t_{i}^{2}+\left(1-t_{i}\right)^{2}\right) Q_{l}$, and where $C_{i}\left(f_{i}, p_{1 i}, p_{2 i}, n_{i} ; t_{i}\right)$ is the expected cost for type $i$ associated with the contract $\left(f_{i}, p_{1 i}, p_{2 i}, n_{i}\right)$.

The following assumption is made to ensure that some task assignments involve multiple tasks.

Assumption 1. $0<\left(Q_{h}-2 Q_{l}\right)$

The inequality states that tasks are complementary for a given agent. To see this more clearly, define $t_{i}^{\prime}=\left(1-t_{i}\right)$. Thus $t_{i}^{\prime}$ is the time that an agent puts into his high cost task. Then the inequality in Assumption 1 states that the cross partial of the principal's expected revenue with respect to $t_{i}$ and $t_{i}^{\prime}$ is positive. Thus the marginal benefit that the principal gets from having an agent perform one task increases in the level of the second task. 
The article proceeds in the following way. I start with the full information case where an agent's time allocation and abilities are observed. This part examines the assignment problem and serves as a benchmark for the rest of the article. I then allow agents to have private information about their time allocation and examine how this affects assignments. Finally, I allow agents to have private information about their abilities also and find the optimal sorting contract.

Full Information. This subsection assumes that agents have no private information and examines assignments in this setting. For any given type $i$, the full information problem can be written down as

$$
\underset{f_{i}, p_{1 i}, p_{2 i}, n_{i} ; t_{i}}{\operatorname{Max}} \pi\left(f_{i}, p_{1 i}, p_{2 i}, n_{i} ; t_{i}\right)
$$

subject to an individual rationality constraint

$$
\left(I R_{i f}\right) \quad V_{i}\left(f_{i}, p_{1 i}, p_{2 i}, n_{i} ; t_{i}\right) \geq u_{0}
$$

The first two propositions of the article examine how assignments depend on relative abilities of agents. The proofs of most of the propositions and lemmas that follow are in Appendix A. ${ }^{4}$

Proposition 1. In the full information case, the optimal contract for the generalist sets $f_{g}=p_{1 g}=$ $p_{2 g}=n_{g}=u^{-1}\left(u_{0}+1\right)$ with $t_{g}=\frac{1}{2}$ and the optimal contract for a specialist sets $f_{s}=p_{1 s}=p_{2 s}=$ $n_{s}=u^{-1}\left(u_{0}+\alpha t_{s}+\beta\left(1-t_{s}\right)\right)$ with $t_{s}>\frac{1}{2}$.

This proposition says that balance matters when jobs differ based on the breadth of tasks. Generalists multi-task (they split time equally cross tasks) whereas specialists spend more time on the task that they are good at.

The intuition for this result can be seen more clearly from the principal's first order conditions. The marginal benefit from splitting time more equally across tasks is given by $\left(1-2 t_{i}\right)\left(Q_{h}-2 Q_{l}\right)$

\footnotetext{
${ }^{4}$ The remaining proofs can be found in separate web appendix at http://research.economics.unsw.edu.au/sprasad/.
} 
whereas the marginal cost to the principal, given that an agent is held to his reservation utility, is given by $\frac{1}{u^{\prime}}\left(\beta_{i}-\alpha_{i}\right)$. Because of complementarities, the marginal benefit of splitting time more equally is strictly positive and the same for both types. The difference in assignments arises because of relative abilities. The marginal cost of getting a generalist to split time more evenly across tasks is 0 whereas in the case of a specialist it is strictly positive.

The next proposition examines how the degree of specialization varies with relative abilities. Because the focus is on specialists, I drop the subscript associated with $t$ for this proposition.

Proposition 2. Fix $\beta$. Suppose $-\frac{u^{\prime \prime}\left(u^{-1}\left(u_{0}+\alpha t+\beta(1-t)\right)\right)}{u^{\prime}\left(u^{-1}\left(u_{0}+\alpha t+\beta(1-t)\right)\right)} \leq \frac{1}{\beta-\alpha}$ for all $t \in[0,1]$ and for all $\alpha \in(0, \beta)$. Then the optimal time allocation $t$ for the full information case is decreasing in $\alpha$. Similarly, if we fix $\alpha$ then $t$ is increasing in $\beta$.

Proposition 2 is useful because it clearly illustrates how this model differs from hierarchy theories. In fact, it forms the basis for the empirical analysis that follows in the article. To make things more concrete, think of a research organization with two tasks: research and supervision and consider the assignment of research scientists (specialists at research). Then Proposition 2 says that holding supervisory ability fixed, scientists with higher research ability should specialize more in research whereas those with lower research ability should perform a mix of research and supervision. This is in contrast to hierarchy theories which suggest that the most able workers should be assigned to management.

To see the intuition for this result look at the marginal cost for getting an agent to split time more evenly across tasks. This is given by $\frac{1}{u^{\prime}\left(u^{-1}\left(u_{0}+\alpha t+\beta(1-t)\right)\right)}(\beta-\alpha)$. Hold $t$ fixed. Then as $\alpha$ falls the term $\beta-\alpha$ increases which increases the marginal cost of splitting time equally whereas the term $\frac{1}{u^{\prime}}$ decreases which reduces the marginal cost of splitting time more equally across tasks. Proposition 2 says if that agents are not too risk averse then the first effect dominates the second effect.

To make the analysis simpler, I make an additional assumption on the cost function of specialists. 
Assumption 2. $\left(Q_{h}-2 Q_{l}\right)<\frac{\beta-\alpha}{u^{\prime}\left(u^{-1}\left(u_{0}+\alpha\right)\right)}$

This assumption says that the marginal cost from getting a specialist to spend a small amount of time on the task he is less able at outweighs the benefits from complementarities. Assumption 2 simplifies the problem and allows me to restrict my attention to assignments where a specialist puts in all of his time into his low cost task.

In the next subsections, I introduce asymmetric information into the model.

Unobservable Time Allocation. In this subsection I assume that an agent's type is observable but that his allocation of time across tasks is not. Though the allocation of time across tasks is not observable, the principal can observe the total time put into both tasks. Allowing total time to be observable, simplifies the analysis and leads to a clearer illustration of the main tradeoffs in the model. In Section 3, I relax the assumption of total time being observable and show that the main results of the model go through qualitatively.

When agents have private information about their time allocation, the principal's problem for any given type $i$ is

$$
\underset{f_{i}, p_{1 i}, p_{2 i}, n_{i} ; t_{i}}{\operatorname{Max}} \pi\left(f_{i}, p_{1 i}, p_{2 i}, n_{i} ; t_{i}\right)
$$

subject to a time allocation or moral hazard constraint given by

$$
t_{i} \in \operatorname{argmax} V_{i}\left(f_{i}, p_{1 i}, p_{2 i}, n_{i} ; t_{i}\right)
$$

and subject to an individual rationality constraint

$$
\underset{t_{i}}{\operatorname{Max}} V_{i}\left(f_{i}, p_{1 i}, p_{2 i}, n_{i} ; t_{i}\right) \geq u_{0}
$$

The next proposition characterizes optimal assignments and contracts for both types when their time allocation is unobservable. 
Proposition 3. When an agent's time allocation is unobservable, the optimal contract for a generalist sets $f_{g}=p_{1 g}=p_{2 g}=n_{g}=u^{-1}\left(u_{0}+1\right)$ with $t_{g}=\frac{1}{2}$ and the optimal contract for the specialist sets $f_{s}=p_{1 s}=p_{2 s}=n_{s}=u^{-1}\left(u_{0}+\alpha\right)$ with $t_{s}=1$.

Proposition 3 says that there is no distortion in assignments when an agent privately observes time allocations. This proposition depends on the simplifications made to the type space. In particular, it depends on the assumption that generalists are equally able at both tasks and that specialists have a very strong advantage in one task.

Unobservable Types and Time Allocation. This subsection looks at the case where agents have private information about their time allocation and their abilities. To make things interesting I assume that $\alpha<1$. This assumption says that a specialist has an absolute advantage over a generalist in the task that he is good at. Also for exposition purposes, I restrict my attention to contracts that pay the same for both kinds of partial success. In section 3, I relax this assumption and show that a variant of the main result in this section still holds. For the rest of this section, denote $p_{1 i}=p_{2 i}=p_{i}$.

Because $\alpha<1$, contracts in the previous subsection are not incentive compatible when types are unobserved. To see this notice that the optimal contract for a specialist sets $t_{s}=1$ and $V_{s}\left(f_{s}, p_{s}, n_{s} ; 1\right)=u\left(p_{s}\right)-\alpha=u_{0}$ whereas the optimal contract for a generalist sets $u\left(p_{g}\right)=u_{0}+1$. By taking the generalist's contract and putting in all his time into his cheaper task a specialist gets $V_{s}\left(f_{g}, p_{g}, n_{g} ; 1\right)=u\left(p_{g}\right)-\alpha=u_{0}+(1-\alpha)>u_{0}$. Figure 1 illustrates the intuition. On the horizontal axis we have outcomes whereas on the vertical axis we have utilities associated with each outcome. A generalist's contract is given by the shaded bar whereas the specialist's contract is shown as the unshaded bar. We can see that the specialist by taking a generalist's contract can get a higher payment for partial success without altering his allocation of time leading to higher utility.

This leads us to a standard result in adverse selection models. A specialist has to be paid an information rent to prevent him from taking a generalist's contract. In this section I will look at 


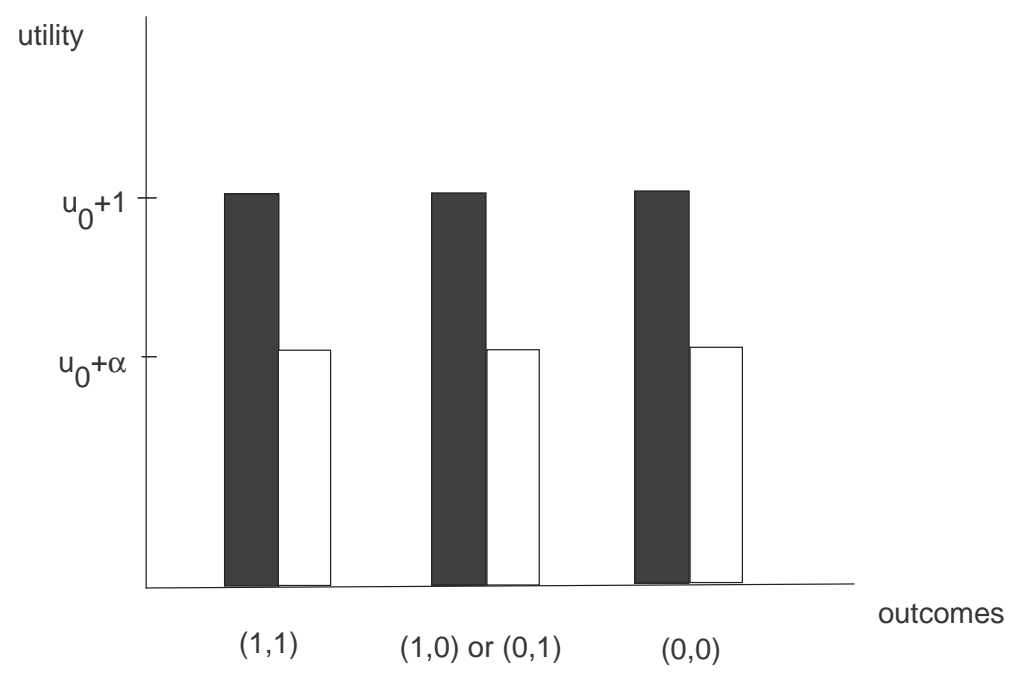

Figure 1: Observable Types

ways in which the principal can reduce this information rent when types are privately observable.

Following Myerson (1982), I use a modified version of the revelation principle and restrict my attention to contracts that satisfy two conditions. First, for each type, the contract specifies how time should be allocated across tasks and a payment for each possible outcome. Second, agents report their types truthfully and choose the time allocation specified for any given type. The principal's problem is given by

$$
\underset{f_{i}, p_{i}, n_{i}, t_{i}}{\operatorname{Max}} \sum_{i} q_{i}\left[t_{i}\left(1-t_{i}\right)\left(Q_{h}-f_{i}-n_{i}\right)+\left(t_{i}^{2}+\left(1-t_{i}\right)^{2}\right)\left(Q_{l}-p_{i}\right)\right]
$$

subject to moral hazard constraints $\left(M H_{i}\right)$, and individual rationality constraints $\left(I R_{i}\right)$ for all types $i$, and additionally subject to incentive compatibility conditions for all types $i$ and $i^{\prime}$ with $i \neq i^{\prime}$,

$\left(I C_{i, i^{\prime}}\right) \quad \operatorname{Max}_{t_{i}} V_{i}\left(f_{i}, p_{i}, n_{i} ; t_{i}\right) \geq \underset{t_{i}}{\operatorname{Max}} V_{i}\left(f_{i^{\prime}}, p_{i^{\prime}}, n_{i^{\prime}} ; t_{i}\right)$ 
As the payments on both partial success outcomes are equal we can rewrite the agent's expected utilities as

$$
V_{i}\left(f_{i}, p_{i}, n_{i} ; t_{i}\right)=u\left(p_{i}\right)+t_{i}\left(1-t_{i}\right)\left(\Delta f_{i}-\Delta p_{i}\right)-\phi_{i}\left(t_{i}\right)
$$

where $\Delta f_{i}=u\left(f_{i}\right)-u\left(p_{i}\right)$ and $\Delta p_{i}=u\left(p_{i}\right)-u\left(n_{i}\right)$

Thus the moral hazard constraints can be rewritten as

$$
t_{g}= \begin{cases}1 & \text { if } \Delta f_{g}-\Delta p_{g}>0 \\ \overline{2} & \text { if } \Delta f_{g}-\Delta p_{g}=0 \\ 0 \text { or } 1 & \text { if } \Delta f_{g}-\Delta p_{g}<0\end{cases}
$$

and

$$
\left(M H_{s}\right) \quad t_{s}= \begin{cases}1 & \text { if } \Delta f_{s}-\Delta p_{s}<\beta-\alpha \\ \frac{1}{2}\left(1+\frac{(\beta-\alpha)}{\left(\Delta f_{s}-\Delta p_{s}\right)}\right) & \text { if } \Delta f_{s}-\Delta p_{s} \geq \beta-\alpha\end{cases}
$$

The expression $\Delta f_{i}-\Delta p_{i}$ has a natural interpretation in terms of complementarities. It is the expression we get if we take the cross partial of equation (1) with respect to $t_{i}$ and $t_{i}^{\prime}$. In other words $\Delta f_{i}-\Delta p_{i}$ measures the extent to which an agent views the tasks as complementary in terms of his preferences. I refer to the term, $\Delta f_{i}-\Delta p_{i}$, as incentive complementarities.

The problem above is complicated and has twelve constraints. I start by leaving out the incentive compatibility conditions of a generalist who claims to be a specialist and check that these constraints hold at the optimum. This reduces the number of constraints to ten. The objective of the next few lemmas is to make the problem simpler to solve by eliminating or simplifying some of the constraints. 
Henceforth let $t_{i}^{*}$ denote agent $i^{\prime} s$ time allocation for a contract $\left(f_{i}, p_{i}, n_{i}\right)$ that satisfies the moral hazard constraint.

The following lemma shows that the optimal contract with privately observable types implements the same time allocation as the case where types are observable. Therefore there is no inefficiency with respect to each type's time allocation.

Lemma 1. In the case with moral hazard and adverse selection, the optimal contract sets $\Delta f_{g}-$ $\Delta p_{g} \geq 0$ with $t_{g}=\frac{1}{2}$ and $\Delta f_{s}-\Delta p_{s} \leq \beta-\alpha$ with $t_{s}=1$.

Lemma 1 states that there is no distortion in the allocation of time because of un-observability of types. A standard model of adverse selection suggests that this should be true for a specialist. What is interesting is that this result holds for a generalist also. To understand this result let us consider a contract with $\Delta f_{g}-\Delta p_{g}<0$ and $t_{g}=1$ that distorts a generalist's time allocation relative to the full information case. Because there is no risk associated with this contract the principal has to pay at least $u^{-1}\left(u_{0}+1\right)$ for partial success in order to satisfy $\left(I R_{g}\right)$. Thus distorting a generalist's first best time allocation does not reduce a specialist's information rent. Two assumptions play an important role in Lemma 1; generalists have equal effort costs across tasks and that payments for partial success are symmetric. Relaxing either of these assumptions will lead to a distortion in the generalist's time allocation. Lemma 1 is also useful because it allows us to explicitly solve for the optimal time allocations and substitute them into the individual rationality and incentive compatibility conditions.

The following lemma states that payments on full and no success should be the same for a generalist.

Lemma 2. In the case with moral hazard and adverse selection, the optimal contract sets $f_{g}=n_{g}$.

Lemma 2 says that whenever contracts are not flat then they are non-monotonic. The result arises because the probabilities associated with full and no success are exactly the same. In order to get a generalist to split his time equally, the principal must reward those outcomes that are 
more likely to arise when time is split evenly. As both of the outcomes, full and no success, have the same probabilities, they convey the same information about how time is split and hence have to be rewarded the same. Differentiating payments on both of these outcomes will only add more risk. Lemma 2 depends crucially on the assumption that the principal can observe the total time allocated to both tasks. As we will see in Section 3, relaxing this assumption will place limits on rewards for the no success outcome. Also from this lemma we know that at the optimum $\Delta f_{g}=-\Delta p_{g}$ and this simplifies things greatly.

The next lemma is extremely useful in simplifying the problem further.

Lemma 3. In the case with moral hazard and adverse selection, the optimal contract sets $p_{s 1}=$ $p_{s 2}=p_{s}$. There is no loss in generality in setting $f_{s 1}=f_{s 2}=f_{s}$ and $n_{s 1}=n_{s 2}=n_{s}$.

Combined with Lemma 1, the above lemma allows us to treat both types of specialists symmetrically. This is because $f_{s j}$ and $n_{s j}$ do not enter into the constraints any more when $t_{s j}=1$. We can, therefore, replace all the constraints with the subscripts $s j$ and $s j^{\prime}$ with the subscripts $s$.

I now show that the generalist's individual rationality constraint must bind. Otherwise the principal can always reduce his costs without violating any of the incentive constraints.

Lemma 4. In the case with moral hazard and adverse selection, the optimal contract has $\left(I R_{g}\right)$ binding.

In Lemma 1 we saw that setting $\Delta f_{g}-\Delta p_{g}<0$ is never optimal because it does not reduce the information rent that a specialist must be paid. This leaves the principal with only one other option to explore, setting $\Delta f_{g}-\Delta p_{g}>0$. The following proposition shows that if contracts satisfy the necessary conditions for optimality that are stated in Lemma's 1 to 4 , then increasing the difference between payments on full and partial success reduces the information rent that has to be paid to a specialist. The way to see this is by looking at the effect $\Delta f_{g}-\Delta p_{g}$ has on the right hand side of $\left(I C_{s g}\right)$.

Proposition 4. Consider the case with moral hazard and adverse selection. Suppose we restrict 
our attention to contracts that satisfy $f_{g}=n_{g}, \Delta f_{g}-\Delta p_{g} \geq 0$ and where $\left(I R_{g}\right)$ binds. Then the utility that a specialist gets from taking a generalist's contract is strictly decreasing in $\Delta f_{g}-\Delta p_{g}$.

An explanation for the intuition of Proposition 4 can be provided through figures 1 and 2 . Let $\left(f_{g}, p_{g}, n_{g}\right)$ be the full information contract in Figure 1 with $u\left(f_{g}\right)=u\left(p_{g}\right)=u\left(n_{g}\right)=u_{0}+1$. Now consider an alternative contract $\left(f_{g}^{\prime}, n_{g}^{\prime}, p_{g}^{\prime}\right)$ that satisfies $\left(I R_{g}\right)$, with $f_{g}^{\prime}=n_{g}^{\prime}$, and with $\Delta f_{g}^{\prime}=2 \epsilon>0$. Substituting the definition of $\Delta f_{g}^{\prime}$ in $\left(I R_{g}\right)$ we have $u\left(f_{g}^{\prime}\right)=u\left(f_{g}\right)+\epsilon$ and $u\left(p_{g}^{\prime}\right)=u\left(p_{g}\right)-\epsilon$.

The contract $\left(f_{g}^{\prime}, n_{g}^{\prime}, p_{g}^{\prime}\right)$ is depicted in Figure 2. Notice that this contract involves a utility loss of $\epsilon$ for partial success and an equal gain of $\epsilon$ in utility for full and no success. A specialist would benefit from this contract if he could place greater weight on the gain in utility and less weight on the loss. But because he has a relative cost advantage in one task he always chooses $t_{s}^{*}>\frac{1}{2}$ and thus the expected utility loss outweighs the expected utility gain.

Another way to view the above result is that the same tradeoff between complementarities and relative abilities that influences assignments can also be used to reduce information rents. An increase in incentive complementarities benefits generalists more than specialists.

Optimal Contract. Proposition 4 gives us a key insight. Increasing information complementarities for a generalist can reduce information rents. What the proposition ignores is that it also increases the risk that a generalist bears because rewards are now tied to outcomes that are random. The optimal contract trades off both of these effects. From now on, I replace $\left(I C_{s g}\right)$ with $\left(I C_{s}\right)$.

We can use all the necessary conditions for an optimal contract derived in the previous subsection to simplify the problem. In particular we know that $\Delta f_{g}-\Delta p_{g} \geq 0$ and $\Delta f_{s}-\Delta p_{s} \leq \beta-\alpha$ which implies $t_{g}^{*}=\frac{1}{2}$ and $t_{s}^{*}=1$. This simplifies $\left(I R_{g}\right)$ and the left hand side of $\left(I C_{s}\right)$ where $t_{i}$ can be replaced by numbers. Only the right hand side of $\left(I C_{s}\right)$ is slightly complicated because $t_{s}$ depends on how large $\Delta f_{g}-\Delta p_{g}$ is relative to $\beta-\alpha$. 


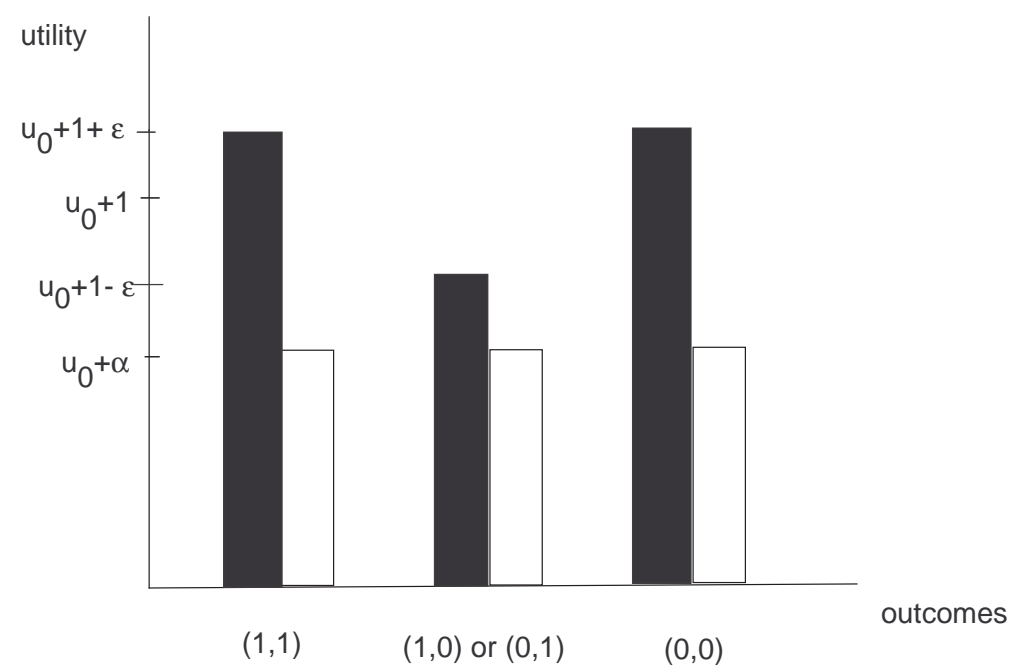

Figure 2: Information Rents

Given the results from the previous subsection the principal's problem can be rewritten. Define $h=u^{-1}$. Using the results from Lemma 1 and substituting the moral hazard constraints for both types, we can rewrite the problem as

$$
\begin{gathered}
\underset{u_{f g}, u_{p g}, u_{p s}}{\operatorname{Max}}-\left(\frac{1}{4} h\left(u_{f g}\right)+\frac{1}{4} h\left(u_{p g}\right)+\frac{1}{2} h\left(u_{p g}\right)\right) \\
\\
\frac{1}{2}\left(u_{f g}+u_{p g}\right)-1 \geq u_{0}
\end{gathered}
$$

$\left(I R_{g}^{\prime}\right)$

$\left(I R_{s}^{\prime}\right)$

$$
u_{p s}-\alpha \geq u_{0}
$$


and the incentive compatibility condition

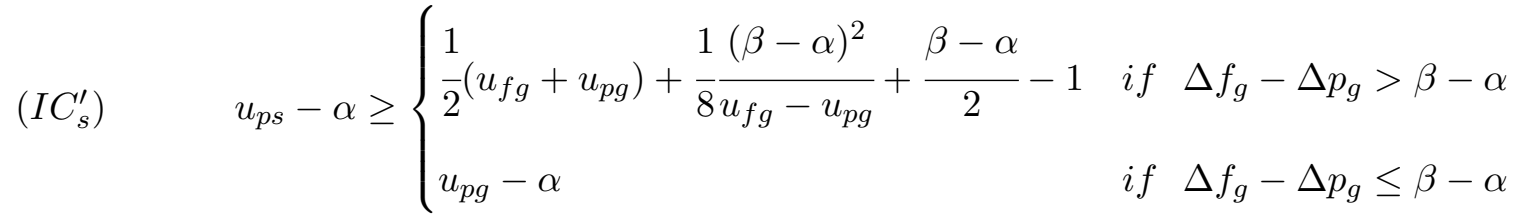

Because $u$ is strictly concave it follows that $h$ is strictly convex and thus the objective function is strictly concave. It can also be checked that the constraint set is convex. I now show that the optimal contract does impose some amount of risk on a generalist.

Proposition 5. Consider the case with moral hazard and adverse selection. The optimal contract for the generalist sets $\Delta f_{g}-\Delta p_{g}>0$ and therefore is more risky than the full information contract. Generalists earn higher expected wages than specialists.

Proposition 5 characterizes the tradeoff between information rents paid to a specialist and the risk that a generalist bears. This proposition can be understood by looking at a hypothetical case where agents are risk neutral. Starting from the full information optimal contract, the principal can reduce $p_{g}$ and increase $f_{g}$ and $n_{g}$ to keep the generalist's expected payment exactly the same without altering his incentives to split his time. From Proposition 4 we know that this reduces the information rent paid to a specialist. Because agents are risk neutral the principal increases his profits. This line of reasoning extends to the case where agents are risk averse because they are risk neutral at the margin. So by increasing $f_{g}$ and $n_{g}$ and by reducing $p_{g}$ by very small amounts the principal can reduce information rents of the specialist without adding substantial risk to a generalist, thereby increasing profits.

It is also useful to look more carefully at why a generalist bears more risk. The first reason is the obvious one; payments vary across outcomes. The second and more important reason is that because probabilities across tasks are independent the probabilities of full and no success are bounded above. When payments are highly contingent on full and no success there is very little an agent can do to ensure that these particular outcomes are realized. 
The key point to note in this section is that the tradeoff between complementarities and relative abilities that plays an important role in the assignment problem also influences the design of sorting incentives. By increasing incentive complementarities for a generalist, the principal makes it more costly for a specialist to lie about his type.

\section{Robustness}

In solving for the optimal contract in the previous section, I made two simplifying assumptions. In this section I will relax these assumptions to show that the results of the model are robust.

Different Payments on Partial Success. So far, I have restricted my attention to contracts that pay equally for both partial success outcomes. This assumption makes the problem tractable and allows for a cleaner exposition of the results. Though the symmetry of the problem suggests that optimal contracts should set payments on partial success equal, it is difficult to establish this result. Setting payments equal on partial success for a generalist has three effects. First, both types of specialists are treated symmetrically with respect to their information rents. Second, because of complementarities the principal can earn a higher expected benefit. Finally, the principal may have to pay a higher expected wage when payments on full and no success exceed payments on partial success. To disentangle all of these effects and find conditions under which payments on partial success are equal is difficult.

In this section, I allow for more general contracts that pay differently for each partial success outcome and show that if complementarities are sufficiently large then the optimal contract still

pays more in the event of full and no success and less in the case of partial success. Proposition 6 states this formally.

Proposition 6. Let $p_{1 g}$ and $p_{2 g}$ denote payments for partial success on task 1 and task 2 respectively. Then the optimal contract sets $t_{s j}=1$ for both specialists. Also if $Q_{h}$ is sufficiently large then the optimal contract for a generalist sets $f_{g}=n_{g}>\max \left\{p_{1 g}, p_{2 g}\right\}$. 
This proposition says that even though the principal does not set payments on partial success equal, he still screens types by varying payments between full and no success and partial success.

Unobservable Total Time. In the previous section I assumed that agents had two sources of private information; their relative abilities across tasks and their allocation of a unit of time across tasks. In this subsection, I add a third source of private information: the total time that an agent allocates to both tasks. This assumption places constraints on the rewards that a principal offers for the no success outcome. In particular, if payments on the no success outcome are too high then the agent will not work at all. To simplify things I focus on a case with one specialist (a specialist at task 1) and where payments on both kinds of partial success are equal. I also assume that the parameters of the model are such that the principal finds it most profitable to make both types of agents allocate their entire unit of time to work.

Denote the time put into the first task by agent $i$ by $t_{i}$ and the time put into the second task by $t_{i}^{\prime}$. The expected utility in this case for a generalist and a specialist are given by

$$
\begin{gathered}
V_{g}\left(f_{g}, p_{g}, n_{g} ; t_{g}\right)=u\left(n_{g}\right)+\left(t_{g}+t_{g}^{\prime}\right)\left(\Delta p_{g}-1\right)+t_{g} t_{g}^{\prime}\left(\Delta f_{g}-\Delta p_{g}\right) \\
V_{s}\left(f_{s}, p_{s}, n_{s} ; t_{s}\right)=u\left(n_{s}\right)+t_{s}\left(\Delta p_{s}-\alpha\right)+t_{s}^{\prime}\left(\Delta p_{s}-\beta\right)+t_{s} t_{s}^{\prime}\left(\Delta f_{s}-\Delta p_{s}\right)
\end{gathered}
$$

The generalist's expected utility clearly shows the incentive problem that the principal faces. As in the previous section $\Delta f_{i}-\Delta p_{i}$ provides incentives to split time. The difference here is that the principal also has to provide incentives for the agent to spend some time working. These incentives are captured by the term $\Delta p_{i}-1$.

I first examine optimal contracts with moral hazard ${ }^{5}$, but with types known, and then go on to look at optimal screening contracts in a case with moral hazard and adverse selection. Also Assumption 1 which says that the tasks are complementary for the principal is replaced by a stronger assumption.

\footnotetext{
${ }^{5}$ Now moral hazard is with respect to both the allocation of time across tasks and the total time exerted.
} 
Assumption 3. $Q_{h}-2 Q_{l}>u^{-1}\left(u_{0}+2\right)+u^{-1}\left(u_{0}\right)-2 u^{-1}\left(u_{0}+1\right)$

Assumption 3 allows me to focus on contracts where a generalist allocates time equally across tasks. In particular, it states that complementarities are sufficiently strong to overcome the risk premium paid to a generalist because of total time being unobservable.

The following Lemma characterizes the optimal contract when the principal can observe types.

Lemma 5. Consider the case where types are observable but where the total time along with the time allocation across tasks is unobservable. Then the optimal contract for a generalist sets $\Delta f_{g}=$ $\Delta p_{g}=1$ and $u\left(n_{g}\right)=u_{0}$ with $t_{g}=\frac{1}{2}$ and the optimal contract for a specialist sets $\Delta f_{s}-\Delta p_{s} \leq \beta-\alpha$ with $t_{s}=1$.

The key intuition underlying Lemma 5 relates to the payment for the no success outcome. This reward cannot be higher than $u_{0}$ otherwise a generalist will do no work and get more than his reservation utility. Thus the principal has to offset this constraint by raising payments on full success to ensure that a generalist splits time equally across tasks. The interesting thing to note here is that even though incentive complementarities are 0 , a generalist still bears risk.

Now I assume that types are not observable along with moral hazard and characterize the optimal contract.

Proposition 7. Consider the case where types are unobservable and where the total time along with the time allocation across tasks is unobservable. Suppose $u^{\prime}\left(u^{-1}\left(u_{0}+1\right)\right)-u^{\prime}\left(u^{-1}\left(u_{0}+2\right)\right)$ is sufficiently small. Then the optimal contract for a generalist sets $u\left(n_{g}\right)=u_{0}, \Delta f_{g}-\Delta p_{g}>0$ and $\Delta p_{g}-1<0$ with $t_{g}=\frac{1}{2}$ and the optimal contract for a specialist sets $\Delta f_{s}-\Delta p_{s} \leq \beta-\alpha$ with $t_{s}=1$.

Proposition 7 says that incentive complementarities play a sorting role even when the total time allocation is unobservable. The only qualification is that an agent's marginal utility must not decrease too much in wealth. The critical point here is that an unobservable total time allocation 
imposes a constraint on the no success payment. Because of this, the only way to increase incentive complementarities is to push payments on full success up and payments on partial success down. But this is costly because an agents utility function is concave. However, if an agents marginal utility does not decline too rapidly in wealth then the benefits of incentive complementarities offset the costs.

Though incentive complementarities play a role, the optimal contract in this setting need not be non-monotone. Only when incentive complementarities are sufficiently large, will payments on no success exceed payments on partial success. This is the main difference between Proposition 7 and it's counterpart in Section 2, Proposition 5.

\section{Implications and Evidence}

Hypothesis and Empirical Specification. To see how this article differs from hierarchy theories, consider the assignment of scientists to managerial positions in a research organization. Suppose there are two tasks, research and supervision; research tasks require scientific knowledge whereas supervision requires good communication, social and decision making skills. Hold supervisory skills fixed. Standard hierarchical models (Calvo and Wellisz (1979), Rosen (1982), Waldman (1984), Murphy (1986), Garicano and Rossi-Hansberg (2006)) suggest that scientists with higher research ability should specialize in supervision. Proposition 2 in this article, however, suggests scientists who are less able at research should combine research with supervision. This can be formally restated in the hypothesis below.

Hypothesis. Hold supervisory skills fixed. Then research scientists with higher research ability should specialize more in research (relative abilities) whereas those with lower research ability should be assigned to a mix of supervision and research tasks (multi-tasking). The hypothesis, can be tested using the following probit specification. 


$$
\begin{gathered}
\operatorname{Prob}\left(M A N A G E R_{i, t+1}\right)=\Phi\left(\beta_{0}+\beta_{1} R E S E A R C H A B I L_{i, t}+\beta_{2} S U P A B I L_{i, t}\right. \\
\left.+\beta_{3} R E S E A R C H A B I L_{i, t} . \operatorname{NNDUSTR} Y_{i, t}+\beta_{4} X_{i, t}\right)
\end{gathered}
$$

where $i$ denotes an individual and where $M A N A G E R_{t+1}$ is a dummy variable which takes the value 1 if a scientist is assigned to management from the date's $t$ to $t+1 .^{6}$ The variables $R E S E A R C H A B I L_{t}$ and $S U P A B I L_{t}$ are measures of research and supervisory ability respectively at date $t$. The vector $X_{t}$ consists of industry, firm and individual controls at date $t$. Finally because measures of research ability may differ across industries, an interaction term with research ability and the industry of a worker is also included in the specification. Given the specification above, the central hypothesis is simple to state. The model in this article suggests that $\beta_{1}<0$ and $\beta_{2}>0$, whereas hierarchy theories suggest that $\beta_{1}>0$ and $\beta_{2}>0$.

Before testing this hypothesis, it is useful to characterize the attributes that an ideal data set should have. Consider research ability first. Because research in non-academic organizations is usually tied to innovation, a useful starting point is patent data. Earlier work on the measurement of innovation relied on patent counts (see Griliches (1990) for a survey) ${ }^{7}$. But subsequent studies have shown that patents are a noisy measure of research ability. For example, Cohen, Nelson, and Walsh (2000) use survey data on R\&D labs in the U.S. manufacturing sector and find that firms often patent for reasons other than profiting directly from their innovations. These reasons include blocking rivals firms from patenting, increasing bargaining power, and preventing litigation. Patent citations are one way to overcome some of these limitations (Hall, Jaffe, and Trajtenberg (2001)). A second aspect of research in non-academic settings that is important is the generation of scientific knowledge. This is because scientific knowledge often serves as a foundation for innovations. ${ }^{8}$ Thus

\footnotetext{
${ }^{6}$ Indexing the variables by t allows me to track job assignments over time. This is necessary in the empirical analysis because workers may be assigned to jobs at different points of time.

${ }^{7}$ Griliches (1990) surveys a number of articles which try to validate the use of patent counts as a measure of research productivity. This includes relating patents to $\mathrm{R} \& \mathrm{D}$ expenditures, commercial innovations, patent renewal rates and fees, and stock market values.

${ }^{8}$ There is a large literature that studies the tradeoff between patenting and publishing. Some studies find that
} 
the ideal data set should also have publication data.

Second, the ideal data set should have measures of supervisory ability. One way to measure this is to consider productivity differences amongst groups of subordinates managed by different supervisors. Third, the data set should have detailed information on tasks, especially related to multi-tasking. Finally, there should be a set of individual, firm and industry level controls to account for heterogeneity in the sample. Fortunately, one data set, the Survey of Doctorate Recipients (SDR), comes sufficiently close to having attributes of the ideal data set.

Survey of Doctorate Recipients. The Survey of Doctorate Recipients (SDR) is a biennial survey of scientists and engineers with doctoral degrees granted by institutions in the United States. The data collection till the year 2001 relied on paper questionnaires whereas computer assisted telephone interviews and self administered online questionnaires were introduced in the year 2003. Four features of this data set are important for this study. First, it has information on the number of patents and publications granted to research scientists over five year periods. I use these as proxies for how able scientists are at research. Second, it has information on the number of workers that a scientist directly supervises which I use as a proxy for supervisory ability. Third, it has detailed information on the tasks that a worker performed in any given period and allows me to track how these tasks changed over time. Fourth, it has detailed information at the level of the individual and industry and to a lesser extent, at the firm level.

To be sure, the data set does have limitations. As mentioned above, though various measures of patent counts have been used in the past to account for research productivity (see Henderson and Cockburn (1996) $)^{9}$, they are noisy. Better measures of research ability would include patent and publication citations. Second, the SDR data set does not have detailed firm level information. This is a limitation, given that studies have shown that firms, even within the same industry, vary in

patents and publications are complementary (Agrawal and Henderson (2002)) whereas others show a conflict between patents and publications (Gittelman and Kogut (2003), Calderini, Franzoni, and Vezzulli (2004)). Though this tradeoff is interesting it lies beyond the scope of this article.

${ }^{9}$ Henderson and Cockburn (1996) study the effect of economies of scale and scope on research productivity. They use patent counts to measure research productivity but only include those patents which were granted in at least two of three major jurisdictions: Japan, Europe and United States. 
their research productivity. ${ }^{10}$ But this is the only data set I know of that has detailed information about tasks, supervisory data and patent and publication measures and thus serves as a good starting point for testing the hypothesis.

In the analysis that follows, I restrict my attention to the two most recent years of the panel, 2001 (corresponds to date $t$ in the empirical specification) and 2003 (corresponds to date $t+1$ in the empirical specification). I start by summarizing activities into the three categories listed in Table 1. These are research activities, supervision, and other activities. The research activities vary in terms of how applied they are. At one end of the spectrum is basic research where research is done for the sake of gaining knowledge whereas at the other end of the spectrum are design and development tasks which are more application oriented. The definition of supervision in the survey is assigning duties to workers and recommending or initiating actions such as hiring, firing or promoting. Because supervision may have a different context for individuals in academic institutions or those who are self employed, I drop both of these groups from the sample.

I then divide scientists into three groups based on their summarized primary and secondary activities. The primary activity is defined as the activity on which a scientist spends the most time on and a secondary activity is the activity he spends the second most time on. The first group is called the research group and their primary and secondary tasks are research tasks. The second group combines research with supervision and is called the research manager group. Finally the last group consists of all the remaining scientists who perform other tasks. This group is called the other scientists group. The main scientist groups that are used in the analysis are listed in Table 2 .

Given this information, I proceed in the following way. I start with the year 2001 and restrict my attention to scientists belonging to the research group. So in terms of the main tasks they

\footnotetext{
${ }^{10}$ Henderson and Cockburn (1996) and Henderson and Cockburn (1994) have shown, within the context of the pharmaceutical industry, that firm dummies have a large effect on research productivity. Similarly Gambardella (1995), using case studies in the pharmaceutical industry, shows that innovation and market performance are cumulative leading to differences amongst firms.
} 
perform this group is homogeneous. ${ }^{11}$ I then track this group over two years to see how their activities change. Those who do tasks that are not research or supervision are dropped from the sample. After dropping outliers there are 1305 observations in the sample. ${ }^{12} 938$ scientists have both their primary and secondary tasks as research in $2003\left(M A N A G E R_{03}=0\right)$ and 367 of them combine research with a supervisory task in $2003\left(M A N A G E R_{03}=1\right)$. No individual in the sample has supervision and management as both a primary and secondary task. Even if we took a broad view of management as involving other administrative tasks, only 32 individuals specialize in management. This suggests that management, within the context of research scientists, is a multi-task activity with both research and supervisory tasks.

The implication that relative abilities matter for assignments requires two pieces of information. First we need to know how workers differ in their abilities across tasks in the year 2001. Second, we need to know how workers are assigned to tasks based on their abilities in 2003.

I use patent and publishing data that survey respondents reported to construct proxies for research ability. Each of these is over a five year horizon from 1996 to 2001. The first proxy for research ability is a dummy variable denoted by $P A T I N V_{01}$ which specifies whether the scientist applied for a patent (named as an inventor). Not all individuals in this group though are granted patents. The second measure of research ability, $P A T G R T_{01}$, lists the number of patents granted to an inventor. The third measure is $P A T C O M_{01}$ which lists the number of patents that resulted in commercial products.

Although innovation is central to non-academic research organizations, the generation of scientific knowledge often serves as a foundation for these innovations. Differentiating innovators based on publications in refereed journals is one way to account for this foundation. Thus I restrict my attention to individuals in the sample who were granted patents and define a new variable $P U B L I S H_{01}$. This variable takes the value 1 if an inventor has published an article in a refereed

\footnotetext{
${ }^{11}$ The main results in this section continue to hold qualitatively when I consider research managers as well in the year 2001.

${ }^{12}$ Details on the construction of the sample are in a separate web appendix at http://research.economics.unsw.edu.au/sprasad/.
} 
journal and 0 otherwise. We should expect that this variable is more important in research oriented firms which provide research services to other firms.

For ability at the supervision task, I use the number of workers supervised directly in the year 2001 as a proxy and this is denoted by the variable $S U P D I R_{01}$. One problem with this is that the number of workers supervised directly may depend on firm size but I control for this using a set of dummies where workers report their firm size. The data set also has information on the number of workers indirectly supervised but this is a more difficult variable to interpret. ${ }^{13}$

There are three main sets of controls. The first set of variables controls for industry using 2002 census industry codes. ${ }^{14}$ There are three main industry codes that scientists come under. About 30 percent of scientists are classified as the professional scientist services group. These firms can be viewed as research intensive firms and the sub categories include research and development services and computer systems design services. The second industry is manufacturing. About 42 per cent of the sample work for these firms. I further subdivide the manufacturing sector into 9 sub-sectors. ${ }^{15}$ Finally about 20 per cent of individuals in the sample come under the category, public administration. ${ }^{16}$

The second set of variables controls for other firm characteristics such as the firm size reported by survey respondents and whether the firm was a new business that was established in the past five years. The final set of controls involves individual and job characteristics. The individual characteristics consist of age dummies over five year intervals, major field of degree, a taste variable dummy which takes the value 1 if an individual viewed intellectual challenge as a very important component when thinking about a job and three measures of job satisfaction relating to intellectual

\footnotetext{
${ }^{13}$ A good scientist may not spend much time managing, but presumably makes some decisions which influence a large number of employees. The model suggests that this scientist should then be assigned to research, as the results later confirm. As expected, the results reverse when managers are included in the sample.

${ }^{14}$ These industry codes were included in the SDR data set for the year 2003. However, from 2001 to 2003 only 77 individuals in the sample changed their employer and job. Of these, I assume, very few would have changed their industry.

${ }^{15}$ These sub-sectors are selected based on whether the sector has at least twenty individuals in the sample. Individuals in these sub-sectors account for around 70 per cent of those associated with manufacturing in the sample.

${ }^{16}$ Public administration is not listed as an industry code in the census and thus had to be added into the data set by the NSF.
} 
challenge, salary and benefits. The job characteristics consist of other activities that a scientist spent at least 10 percent of his time on, the extent to which a scientist does applied research, the hours worked per week on a job, job salary in 2001, the number of workers supervised indirectly, the year a scientist started a job and whether a scientist switched employers during the period 1999 to 2001 . Some of the important controls used in the analysis are listed in Appendix B. ${ }^{17}$

Table 3 shows the summary statistics across groups for some of the main variables in the analysis. Though the research group does have higher averages for some patent measures, this difference does not seem very large. There could be two possible reasons for this. First those with a higher number of patents presumably supervised more workers in 2001 and thus were named on a larger number of patents. This effect can be controlled for using the number of workers directly supervised. Second, those with a large number of patents possibly have other traits that are positively correlated with managerial ability such as a good work ethic, ambition and responsibility. I use the salary of a worker in 2001 to control for this effect.

The summary statistics also give us information on how managerial jobs differ from research jobs. The average number of workers directly supervised in 2003 for the research manager group goes up by 86.9 per cent when compared to 2001 levels whereas the percentage increase is only 13.8 for those in the research group. Another interesting feature is that those who switch to management are on average younger than those who do not. It appears as though non-academic scientists who switch career tracks do so relatively earlier in their careers. To account for the fact that switching patterns may vary across different age groups, I control for age non-linearly using age dummies over five year intervals.

Table 4 reports marginal effects of the probit model evaluated at the mean. There are four columns. In the first three regressions, I drop the interaction term with industry and focus on the effect of research ability on job assignments alone. Consider the first column where the patent variable is a dummy which indicates whether a scientist was named an inventor on a patent application

\footnotetext{
${ }^{17} \mathrm{~A}$ complete list of controls can be found on the web at http://research.economics.unsw.edu.au/sprasad/.
} 
or not for the years 1996 to 2001. Being named an inventor on a patent application over this period decreases the probability of switching to the research manager group from 0.256 to 0.198 . Thus the probability drops by about 22 percent and this change is significant at the five per cent level. Similarly the marginal effect for the number of patents granted on the probability of switching is negative and significant at the ten per cent level. The third regression shows the marginal effect of PATCOM $M_{01}$ on becoming a manager in 2003 and though the sign of the coefficient is negative, it is insignificant. A possible reason for this is that very few individuals in the sample have patents that resulted in commercial products.

Finally, consider the dummy variable $P U B L I S H_{01}$ and interact this with the industry dummy variable $S C I S E R V_{01}$ which takes the value 1 if an individual belongs to the professional scientist services group. This group provides research services to other firms and hence publications in addition to innovation should serve as an important measure of research ability. The theory in this article then suggests that $\beta_{3}$ should be negative. Column IV shows the marginal effects associated with this interaction term. Inventors in the professional scientist services group who publish are 19 per cent less likely to switch to management when compared to scientists in other organizations. Interestingly, the marginal effect associated with publishing for inventors not belonging to research service firms is positive (though insignificant). One possible reason is that in organizations where the expertise of most individuals differs from outsiders who can provide useful information, a "gatekeeper" is needed to keep abreast and "communicate" these latest findings (Cohen and Levinthal (1990)). This information may be best communicated through management jobs. ${ }^{18} 19$

The empirical test is straightforward but provides a distinction between this model which emphasizes relative abilities and standard managerial assignment models which stress on absolute abilities. Another difference from the existing literature is the focus on supervision as a multi-task

\footnotetext{
${ }^{18}$ It is useful to note that all of the coefficients associated with other industries (using professional scientists as the base group) are negative (except for the public administration group) and some are even significant. This could be because research service firms have a very narrow focus with the only employees being researchers.

${ }^{19} \mathrm{I}$ also test for functional form using a likelihood ratio test and find that the statistic is significant at the five percent level.
} 
activity rather than a specialized task.

Other Sources of Evidence. This subsection supplements the results of the SDR, by considering other sources of evidence. These sources include case studies, newspaper articles, reports from human resource consultants and interviews with technical and human resource personnel. The advantage of this approach is that it sheds light on the reasons firms use to assign workers to jobs. The primary focus in this section is on "dual career tracks". I first describe these career tracks, then discuss why firms offer them and finally document job assignments of the top technical personnel in some organizations. The main objective of this subsection is to suggest that relative abilities play an important role in some managerial settings. ${ }^{20}$

A dual career track offers two career possibilities for technical professionals in an organization: they can continue to do technical jobs or move to a management job. ${ }^{21}$ These career choices are usually made in consultation with human resource managers and based on the skills and preferences of a technical employee. Several firms use dual career tracks. These include technology oriented companies such as International Business Machines (IBM) and American Telephone and Telegraph Company (AT\&T) ${ }^{22}$ and pharmaceutical firms such as Merck and Co and Eli Lilly (Thayer (1998)).

The reason firms offer these career tracks is clearly documented in a report by a leading human resource consulting firm, Haygroup. "Alongside the evolution in work, organization design and reward structures, came a growing awareness that technical specialists/experts were often not effective in leadership roles-particularly those that included leadership of people." Furthermore, the report suggests that people who are excellent at what they do should not be pushed into managerial roles that they are not equipped to perform. ${ }^{23}$ Similarly, a human resources director at

\footnotetext{
${ }^{20}$ Whereas the focus of this subsection is on relative abilities, there is a literature in human resource management that emphasizes the multi-task nature of managerial jobs in research settings (see James (2002) and Cordero and Farris (2004)).

${ }^{21}$ An interesting account of how these career tracks were designed at National Semiconductor and British Petroleum Exploration (BPX) can be found at Moravec and McKee (1990) and Moravec (1993).

${ }^{22}$ Parallel Lines: Companies Create New Ways to Promote Employees-Without Making Them Bosses, Wall Street Journal, 1993.

${ }^{23}$ Dual Career Tracks, Playing to People's Strengths and Recognizing the Worth of Their Contributions, Haygroup Working Paper, 2004.
} 
the pharmaceutical firm, Eli Lilly, suggests that without these career tracks, the firm was "losing good scientists over to administration and probably had people doing work that was'nt as much to their calling (see Thayer (1998)). All of these descriptions of dual career tracks suggest that relative abilities are important for managerial assignments. ${ }^{24}$

The role of relative abilities is further emphasized when studying the assignments of top scientists in research organizations. Most of these organizations have jobs with the title of "fellow" or "research associate" (the title of this position varies across different organizations). These positions are for distinguished scientists in a firm and usually come with substantial freedom to pursue research. A historical account of the DuPont Company provides an accurate description of the job of a research associate and the qualifications required. The research associate program was instituted by the Rayon department in Du Pont in 1946 and to be selected, a scientist had to have the following qualifications: "men of long service, distinguished scientific attainments and high creative potential, with capabilities for originating, organizing and conducting their own research programs". Furthermore, these scientists had substantial freedom to pursue research topics of their own interest and were encouraged to publish and present their work (Hounshell and Smith (1988)). IBM Research and AT\&T labs have similar programs, where exceptional scientists are named research fellows and allowed to choose their own research projects. There are a few qualifications though. Interviews with IBM fellows indicate that some of them with good managerial skills do take on management roles (Winslett (2003), Winslett (2005)). Second, in many cases, fellows do have additional leadership responsibilities, besides doing research. ${ }^{25}$ However, despite this emphasis on leadership, these jobs are mainly research jobs. In summary, all of the examples above point to the importance of relative abilities when assigning technical workers to managerial positions in an organization.

\footnotetext{
${ }^{24}$ Another related objective of dual career tracks is to ensure that workers are satisfied with their jobs and career prospects so that they do not leave the firm.

${ }^{25}$ For example at a chemicals company, Rohm and Haas, fellows are responsible for developing new technologies and mentoring junior scientists (Thayer (1998)).
} 


\section{Conclusion}

This article examines task assignments in a multi-task setting. Assignments are determined by a tradeoff between relative abilities and complementarities between tasks. As a result, workers with balanced abilities get assigned to multiple tasks whereas those with a relative advantage in one task specialize more in that task.

I then assume that workers have private information about their abilities and their allocation of time across tasks and show how contracts get workers to reveal this information. The optimal sorting contract for a multiple task assignment pays more in the event of full success and no success and less in the event of partial success. This contract reduces the information rent of a specialist who finds it more costly to split his time equally across tasks but increases the risk that a generalist bears.

Finally, I use patent and publication data on research scientists to study managerial assignments in a multi-task setting. Using data on research scientists, I show that holding supervisory ability fixed, scientists with more patents and inventors in research organizations who publish are less likely to switch to a mix of research and supervisory tasks. I supplement this analysis with other sources of evidence such as case studies, reports, and interviews.

Though this article primarily addresses job assignments in research organizations, the analysis should hold across other occupations as well. Consider managerial assignments for lawyers, consultants and academics. In all of these cases management can be viewed as a broad job with very different tasks; some tasks are related to an individual's area of expertise whereas other tasks require supervisory skills. This article can also be applied to non-managerial settings. For example, consider economists in business schools versus economists in economics departments. Business schools give equal importance to teaching business students and doing research whereas traditional economics departments tend to emphasize the latter. ${ }^{26}$ The framework developed here can be used to analyze how different economists are assigned across these jobs and how compensation schemes

\footnotetext{
${ }^{26}$ I would like to thank a referee for suggesting this example.
} 
sort them. Though the model in this article abstracts from hierarchies, the basic tradeoff between relative abilities and complementarities should hold in a hierarchical model as well. This is an area for future research.

\section{Appendix A}

Proof of Proposition 1: This proof consists of two parts. The first part shows that optimal contracts involve agents bearing no risk and the second part looks at time allocations for both types. For now consider two types, a generalist and a specialist at task 1. The proof for a specialist at task 2 is exactly the same but requires different notation. Fix $t_{i} \in(0,1)$ and suppose to the contrary that the optimal contract $\left(f_{i}, p_{1 i}, p_{2 i}, n_{i}\right)$ has payments varying over some outcomes. Consider a new contract $\left(f_{i}^{\prime}, p_{1 i}^{\prime}, p_{2 i}^{\prime}, n_{i}^{\prime}\right)$ given by

$$
f_{i}^{\prime}=p_{1 i}^{\prime}=p_{2 i}^{\prime}=n_{i}^{\prime}=t_{i}\left(1-t_{i}\right)\left(f_{i}+n_{i}\right)+t_{i}^{2} p_{1 i}+\left(1-t_{i}\right)^{2} p_{2 i}-\epsilon
$$

where $\epsilon>0$. As $u$ is strictly concave, for a sufficiently small $\epsilon$ we have

$$
\begin{gathered}
u\left(t_{i}\left(1-t_{i}\right)\left(f_{i}+n_{i}\right)+t_{i}^{2} p_{1 i}+\left(1-t_{i}\right)^{2} p_{2 i}-\epsilon\right)>t_{i}\left(1-t_{i}\right)\left(u\left(f_{i}\right)+u\left(n_{i}\right)\right)+t_{i}^{2} u\left(p_{1 i}\right)+\left(1-t_{i}\right)^{2} u\left(p_{2 i}\right) \\
\geq u_{0}+\alpha_{i} t_{i}+\beta_{i}\left(1-t_{i}\right)
\end{gathered}
$$

Thus the new contract, $\left(f_{i}^{\prime}, p_{1 i}^{\prime}, p_{2 i}^{\prime}, n_{i}^{\prime}\right)$, satisfies $\left(I R_{i f}\right)$ and is less costly than the contract $\left(f_{i}, p_{1 i}, p_{2 i}, n_{i}\right)$ which is a contradiction. Thus it must be the case that optimal contracts set payments equal for all outcomes.

For the second part of the proof, let $w_{i}$ denote the constant wage that an agent receives. Because payments are equal for all outcomes, $\left(I R_{i f}\right)$ can be written as $u\left(w_{i}\right) \geq u_{0}+\alpha_{i} t_{i}+\beta_{i}\left(1-t_{i}\right)$. 
The individual rationality constraint above has to bind or else the principal can reduce $w_{i}$ by small amount and increase overall profits. Thus $w_{i}=u^{-1}\left(u_{0}+\alpha_{i} t_{i}+\beta_{i}\left(1-t_{i}\right)\right)$.

Define $h=u^{-1}$. Then the principal solves the following maximization problem

$$
\underset{t_{i}}{\operatorname{Max}_{i}} t_{i}\left(1-t_{i}\right) Q_{h}+\left(t_{i}^{2}+\left(1-t_{i}\right)^{2}\right) Q_{l}-h\left(u_{0}+\alpha_{i} t_{i}+\beta_{i}\left(1-t_{i}\right)\right)
$$

The first order conditions are given by

$$
\left(1-2 t_{i}\right)\left(Q_{h}-2 Q_{l}\right)-h^{\prime}\left(u_{0}+\alpha_{i} t_{i}+\beta_{i}\left(1-t_{i}\right)\right)\left(\alpha_{i}-\beta_{i}\right) \geq 0
$$

Because a generalist finds tasks equally costly, and as $Q_{h}>2 Q_{l}$ the solution to this first order condition sets $t_{g}=\frac{1}{2}$. As $\beta>\alpha$ the optimal time allocation for a specialist is $t_{s}>\frac{1}{2}$.

Proof of Proposition 2: The first order necessary conditions for an interior solution are given by

$$
(1-2 t)\left(Q_{h}-2 Q_{l}\right)-h^{\prime}\left(u_{0}+\alpha t+\beta(1-t)\right)(\alpha-\beta)=0
$$

Using the implicit function theorem we have

$$
\frac{d t}{d \alpha}=-\frac{\left(-h^{\prime}+(\beta-\alpha) h^{\prime \prime} t\right)}{-\left(2\left(Q_{h}-2 Q_{l}\right)+(\beta-\alpha)^{2} h^{\prime \prime}\right)}
$$

Thus $\frac{d t}{d \alpha} \leq 0$ iff $-h^{\prime}+(\beta-\alpha) h^{\prime \prime} t_{i} \leq 0$. Using the inverse function theorem we have $\frac{d t}{d \alpha} \leq 0$ iff $t \leq-\frac{u^{\prime}}{u^{\prime \prime}(\beta-\alpha)}$. As $-\frac{u^{\prime \prime}\left(u^{-1}\left(u_{0}+\alpha t+\beta(1-t)\right)\right)}{u^{\prime}\left(u^{-1}\left(u_{0}+\alpha t+\beta(1-t)\right)\right)} \leq \frac{1}{\beta-\alpha}$ it follows that $\frac{d t}{d \alpha} \leq 0$.

Now consider the case where $\alpha$ is fixed and we vary $\beta$. Once again from the implicit function theorem, we have 


$$
\frac{d t}{d \beta}=-\frac{\left(h^{\prime}-(\beta-\alpha) h^{\prime \prime} t\right)}{-\left(2\left(Q_{h}-2 Q_{l}\right)+(\beta-\alpha)^{2} h^{\prime \prime}\right)}=-\frac{d t}{d \alpha} \geq 0
$$

Thus $t$ is increasing in $\beta$. A similar result holds for corner solutions as well.

Proof of Proposition 3: Consider a generalist first. When payments are equal for all outcomes, a generalist's expected utility does not depend on $t$. Thus the optimal contract in the full information case also satisfies the moral hazard constraint. Now consider a specialist. When payments are equal across outcomes the only part of a the specialist's utility function that depends on $t$ is his cost function. Because $\alpha<\beta$ a specialist always chooses $t_{s}=1$ and once again the full information contract satisfies the specialist's moral hazard constraint.

Proof of Proposition 4: As $f_{g}=n_{g}$ we have $\Delta f_{g}-\Delta p_{g}=2 \Delta f_{g} \geq 0$. The right hand side of $\left(I C_{s g}\right)$ is given by

$$
\underset{t_{s}}{M a x} V_{s}\left(f_{g}, p_{g}, n_{g} ; t_{s}\right)=\underset{t_{s}}{M a x} u\left(p_{g}\right)-\alpha t_{s}-\beta\left(1-t_{s}\right)+2 t_{s}\left(1-t_{s}\right) \Delta f_{g}
$$

Combining $\left(I R_{g}\right)$ and the definition of $\Delta f_{g}$ and substituting into $\underset{t_{s}}{M_{s}} V_{s}\left(f_{g}, p_{g}, n_{g} ; t_{s}\right)$ we have

$$
\operatorname{Max}_{t_{s}} V_{s}\left(f_{g}, p_{g}, n_{g} ; t_{s}\right)=M_{t_{s}} a x \quad u_{0}+1-\alpha t_{s}-\beta\left(1-t_{s}\right)-\frac{1}{2} \Delta f_{g}+2 t_{s}\left(1-t_{s}\right) \Delta f_{g}
$$

Define $t_{s g}^{*}$ as the optimal choice of time by a specialist when he is offered a generalist's contract $\left(f_{g}, p_{g}, n_{g}\right)$. Using the envelope theorem we get

$$
\frac{d V_{s}\left(f_{g}, p_{g}, n_{g} ; t_{s g}^{*}\right)}{d \Delta f_{g}}=-\frac{1}{2}+2 t_{s g}^{*}\left(1-t_{s g}^{*}\right)<0
$$

where the last inequality follows from the fact that $t_{s g}^{*}>\frac{1}{2}$. Thus the result follows. 
Proof of Proposition 5: There are two possible solutions. First if $\Delta f_{g}-\Delta p_{g} \geq \beta-\alpha$ at the optimum then we are done. Consider the other case with $\Delta f_{g}-\Delta p_{g}<\beta-\alpha$. Then the first order necessary conditions are given by

$$
\left(\begin{array}{cc}
-\frac{1}{4} \frac{1}{u^{\prime}\left(f_{g}\right)} \\
1 \\
-\frac{1}{4} \frac{1}{u^{\prime}\left(p_{g}\right)} \\
1 \\
-\frac{1}{2} \frac{1}{u^{\prime}\left(p_{s}\right)}
\end{array}\right)=-\lambda\left(\begin{array}{c}
1 \\
\overline{2} \\
1 \\
\overline{2} \\
0
\end{array}\right)+\mu\left(\begin{array}{c}
0 \\
1 \\
-1
\end{array}\right)+\gamma\left(\begin{array}{c}
0 \\
0 \\
-1
\end{array}\right)
$$

along with the complementary slackness conditions associated with the constraints and multipliers.

Now consider two possible cases. First consider the case where $\left(I R_{s}^{\prime}\right)$ does not bind. The complementary slackness conditions imply $\gamma=0$. Combining the first order conditions we have

$$
\frac{1}{4}\left(\frac{1}{u^{\prime}\left(f_{g}\right)}-\frac{1}{u^{\prime}\left(p_{g}\right)}\right)=\frac{1}{2} \frac{1}{u^{\prime}\left(p_{s}\right)}>0
$$

As $u$ is strictly increasing and strictly concave it follows that $f_{g}>p_{g}$.

Next, consider the case with $\gamma>0$. Suppose to the contrary that the optimal contract $\left(f_{g}, p_{g}, n_{g}\right)$ sets payments on full and partial success equal. It follows from $\left(I R_{g}^{\prime}\right)$ that $u\left(f_{g}\right)=u\left(p_{g}\right)=u_{0}+1$. As $\gamma>0$ the complementary slackness conditions imply $u\left(p_{s}\right)=\alpha+u_{0}$. But this violates $\left(I C_{s}^{\prime}\right)$ and contradicts the optimality of $\left(f_{g}, p_{g}, n_{g}\right)$. From Lemma 1 it follows that $f_{g}>p_{g}$.

Finally by setting $f_{s}=n_{s}=0$ the contract also satisfies the incentive compatibility conditions for both specialists that we left out at the start of the problem.

To show why generalists earn higher expected wages first notice that $u\left(p_{s}\right)<u_{0}+1$. If this were not true, the full information contract would yield higher profits for the principal. Also from $\left(I R_{g}\right)$ we know that 


$$
t_{g}\left(1-t_{g}\right)\left(u\left(f_{g}\right)+u\left(n_{g}\right)\right)+\left(t_{g}^{2}+\left(1-t_{g}\right)^{2}\right) u\left(p_{g}\right)=u_{0}+1
$$

Because $u$ is strictly concave it follows that

$t_{g}\left(1-t_{g}\right)\left(u\left(f_{g}\right)+u\left(n_{g}\right)\right)+\left(t_{g}^{2}+\left(1-t_{g}\right)^{2}\right) u\left(p_{g}\right)<u\left(t_{g}\left(1-t_{g}\right)\left(f_{g}+n_{g}\right)+\left(t_{g}^{2}+\left(1-t_{g}\right)^{2}\right) p_{g}\right)$

Combining the three inequalities above and as $u$ is strictly increasing we have

$$
t_{g}\left(1-t_{g}\right)\left(f_{g}+n_{g}\right)+\left(t_{g}^{2}+\left(1-t_{g}\right)^{2}\right) p_{g}>p_{s}
$$

Thus generalists earn higher expected wages.

\section{Appendix B- Variable List}

- PROXIES FOR RESEARCH ABILITY

- PATINV $V_{t}=$ a dummy variable which takes the value 1 if a person is named as an inventor on a patent application from period $t-5$ to $t$;

- PATGRT $T_{t}=$ number of patents that are granted to an individual from period $t-5$ to $t$;

- PATCOM $M_{t}=$ number of patents that are granted to an individual from period $t-5$ to $t$ which result in a commercial product;

- PUBLISH $H_{t}=$ a dummy variable which takes the value 1 if an individual has articles published in refereed journals from period $t-5$ to $t$. This variable is only defined for individuals who were granted patents.

- PROXIES FOR SUPERVISORY ABILITY

- SUPDIRt $=$ the number of people that an individual supervises directly at date $t$;

\section{- INDUSTRY}

These industry codes associated with each individual are based on the 2002 Census Industry Codes. 
- SCISERV $V_{t}=$ a dummy variable which takes the value 1 if an individual belongs to the Professional and Scientific Services category.

- $S A L A R Y_{t}=$ basic annual salary before deductions at date $t$. Excludes bonuses;

- $S A L 10000_{t}=\frac{S A L A R Y}{10000} ;$

- $A G E_{t}=$ the age of an individual at date $t$;

- JOB ACTIVITIES

- SUPIND $D_{t}=$ the number of people that an individual supervises indirectly at date $t$;

- $M G M T_{t}=$ a dummy variable which takes a value of 1 if an individual spends at least 10 per cent of his time on supervision and management at date $t$; 


\section{References}

Agrawal, A. And Henderson, R. "Putting Patents in Context: Exploring Knowledge Transfer from MIT." Management Science, Vol. 48 (2002), pp. 44-60.

BAker, G. "Incentive Contracts and Performance Measurement." Journal of Political Economy, Vol. 100 (1992), pp. 598-614.

Bardsley, P. "Multi-task Agency: a Combinatorial Model." Journal of Economic Behavior and Organization, Vol. 44 (2001), pp. 233-248.

Becker, G. And Murphy, K. "The Division of Labor, Coordination Costs and Knowledge." Quarterly Journal of Economics, Vol. 107 (1992), pp. 1137-1160.

Calderini, M., Franzoni, C. And Vezzulli, A. "If Star Scientists do not Patent: An Event History Analysis of Scientific Eminence and the Decision to Patent in the Academic World." Working paper, 2004.

Calvo, G. And Wellisz, S. "Hierarchy, Ability and Income Distribution." Journal of Political Economy, Vol. 86 (1979), pp. 991-1010.

Cohen, W. And Levinthal, D. "Absorptive Capacity: A New Perspective on Learning and Innovation." Administrative Science Quarterly, Vol. 35 (1990), pp. 128-152.

Cohen, W., Nelson, R. And Walsh, J. "Protecting their Intellectual Assets: Appropriability Conditions and why U.S. Manufacturing Firms Patent." NBER Working Paper Series, 2000.

Cordero, R. and FArris, G. "Supervisors in R\&D Laborataries: Using Technical, People, and Administrative Skills Effectively." IEEE Transactions on Engineering Management, Vol. 51 (2004), pp. 19-30.

Ferreira, D. And SAH, R. "Who gets to the top: Generalists versus Specialists in Organizations." Working Paper, 2007. 
Gambardella, A. Science and Innovation: The US Pharmaceutical Industry During the 1980s, Cambridge: Cambridge University Press, 1995.

Garicano, L. and Rossi-Hansberg, E. "Organization and Inequality in a Knowledge Economy." Quarterly Journal of Economics, Vol. 121 (2006), pp. 1383-1435.

Geanakoplos, J. and Milgrom, P. "A Theory of Hierarchies Based on Limited Managerial Attention." Journal of the Japanese and International Economies, Vol. 5 (1991), pp. 205-225.

Gibbons, R. And Waldman, M. "Task Specific Human Capital." American Economic Review, Vol. 94 (2004), pp. 203-207.

Gittelman, M. And Kogut, B. "Does Good Science Lead to Valuable Knowledge? Biotechnology Firms and the Evolutionary Logic of Citation Patterns." Management Science, Vol. 49 (2003), pp. 366-382.

Griliches, Z. "Patent Statistics as Economic Indicators: A Survey." Journal of Economic Literature, Vol. 28 (1990), pp. 1661-1707.

Grossman, S. And O. Hart "An Analysis of the Principal-Agent Problem." Econometrica, Vol. 51 (1983), pp. 7-45.

Hall, B., Jaffe, A., And Trajtenberg, M. "The NBER Patent Citations Data File: Lessons, Insights and Methodological Tools." Working Paper, 2001.

Harris, M. And Raviv, A. "Organization Design." Management Science, Vol. 48 (2002), pp. $852-865$.

Hart, O. And Moore, J. "On the Design of Hierarchies: Coordination versus Specialization." Journal of Political Economy, Vol. 113 (2005), pp. 675-702.

Henderson, R. And Cockburn, I. "Measuring Competence? Exploring firm effects in drug discovery." Strategic Management Journal, Vol. 15 (1994), pp. 63-84. 
— "Scale, Scope, and Spillovers: The Determinants of Research Productivity in Drug Discovery." The RAND Journal of Economics, Vol. 27 (1996), pp. 32-59.

Holmstrom, B. "Moral Hazard and Observability." Bell Journal of Economics, Vol. 10 (1979), pp. 74-91.

Holmstrom, B. And Milgrom, P. "Aggregation and Linearity in the Provision of Intertemporal Incentives." Econometrica, Vol. 55 (1987), pp. 303-328.

"Multitask Principal-Agent Analysis: Incentive Contracts, Job Ownership and Asset Design." Journal of Law, Economics and Organization, Vol. 7 (1991), pp. 24-52.

Hounshell, D. And Smith, J. Science and Corporate Strategy: DuPont RED, 1902-1980, Cambridge: Cambridge University Press, 1988.

Iтон, H. "Job Design, Delegation and Cooperation: A Principal-Agent Analysis." European Economic Review, Vol. 38 (1994), pp. 691-700.

James, W. "Best HR Practices for Todays Innovation Management." Research-Technology Management, Vol. 45 (2002), pp. 57-60.

Lazear, E. "Performance Pay and Productivity." American Economic Review, Vol. 90 (2000), pp. 1346-1361.

__Entrepreneurship." Journal of Labor Economics, Vol. 23 (2005), pp. 649-680.

"Output-Based Pay: Incentives or Sorting?" Research in Labor Economics, Vol. 23 (2005), pp. 1-25.

Lazear, E., And Rosen, S. "Rank-Order Tournaments as Optimum Labor Contracts." Journal of Political Economy, Vol. 89 (1981), pp. 841-864.

Lindbeck, A. And Snower, D. "Multitask Learning and Reorganization of Work: From Tayloristic to Holistic Organization." Journal of Labor Economics, Vol. 18 (2000), pp. 353-376. 
MacDonald, G. And Marx, L. "Adverse Specialization." Journal of Political Economy, Vol. 109 (2001), pp. 864-899.

Moravec, M. "How BPX Implemented Dual-Career Ladders." Research-Technology Management, Vol. 361 (1993), pp. 39-44.

Moravec, M. And McKee, B. "Designing Dual Career Paths and Compensation." Personnel (AMA), Vol. 67 (1990), pp. 4-9.

Murphy, K. "Incentives, Learning, and Compensation: A Theoretical and Empirical Investigation of Managerial Labor Contracts." The Rand Journal of Economics, Vol. 17 (1986), pp. $59-76$.

Myerson, R. "Optimal Coordination Mechanisms in generalized Principal-Agent Problems." Journal of Mathematical Economics, Vol. 10 (1982), pp. 67-81.

PrAT, A. "Hierarchies of Processors with Endogenous Capacities." Journal of Economic Theory, Vol. 77 (1997), pp. 214-222.

Rosen, S. "Substitution and Division of Labor." Economica, Vol. 45 (1978), pp. 235-250.

"Authority, Control and the Distribution of Earnings." Bell Journal of Economics, Vol. 13 (1982), pp. 311-323.

Sattinger, M. "Comparative Advantage and the Distribution of Earnings and Abilities." Econometrica, Vol. 43 (1975), pp. 455-468.

Thayer, A. "Dual Career Ladders." Chemical $E$ Engineering News, Vol. 76 (1998), pp. 51-56.

Waldman, M. "Worker Allocation, Hierarchies and the Wage Distribution." Review of Economic Studies, Vol. 51 (1984), pp. 95-109. 
Winslett, M. "Pat Selinger Speaks Out on Why System R Was So Successful, Interactions with the INGRES and QBE Teams, How to Do Techology Transfer, How to Manage Difficult People, How to Mentor 3,000 People at Once, and More." SIGMOD Record, Vol. 32 (2003), pp. $93-103$.

"Bruce Lindsay Speaks Out on System R, Benchmarking, Life as an IBM Fellow, the Power of DBAs in the Old Days, Why Performance Still Matters, Heisenbugs, Why He Still Writes Code, Singing Pigs, and More." SIGMOD Record, Vol. 34 (2005), pp. 71-79. 
Table 1: Summarized Work Activities

\begin{tabular}{|c|c|}
\hline Summarized Activities & Activities \\
\hline Research & $\begin{array}{c}\text { Basic Research } \\
\text { Applied Research } \\
\text { Development and Design }\end{array}$ \\
Supervision & Managing and Supervising \\
Other & Computer Applications \\
& Accounting, finance, contracts \\
Employee Relations \\
Sales, Purchasing, Marketing \\
Quality or Productivity Management \\
Other activities
\end{tabular}

Table 2: Groups

\begin{tabular}{|c|c|c|}
\hline Groups & Summarized Activities & Description \\
\hline Researchers & $\begin{array}{c}\text { Primary: Research } \\
\text { Secondary: Research }\end{array}$ & $\begin{array}{c}\text { Research tasks } \\
\text { only }\end{array}$ \\
Research & $\begin{array}{c}\text { Primary: Research } \\
\text { Managers }\end{array}$ & $\begin{array}{c}\text { Cocondary: Supervision } \\
\text { or }\end{array}$ \\
& $\begin{array}{c}\text { Primary: Supervision } \\
\text { with }\end{array}$ \\
& Secondary: Research & \\
\hline \multicolumn{2}{|c}{} \\
\hline
\end{tabular}


Table 3: Summary Statistics

\begin{tabular}{|c|c|c|}
\hline & $\begin{array}{c}\text { Research03 } \\
\mathrm{N}=938\end{array}$ & $\begin{array}{c}\text { Research Manager03 } \\
\mathrm{N}=367\end{array}$ \\
\hline$P A T I N V_{01}$ & $\begin{array}{l}0.442 \\
(0.496)\end{array}$ & $\begin{array}{l}0.414 \\
(0.493)\end{array}$ \\
\hline$P A T G R T_{01}$ & $\begin{array}{l}0.973 \\
(2.171)\end{array}$ & $\begin{array}{l}0.833 \\
(1.638)\end{array}$ \\
\hline PATCOM $M_{01}$ & $\begin{array}{l}0.319 \\
(0.893)\end{array}$ & $\begin{array}{l}0.321 \\
(0.849)\end{array}$ \\
\hline AGE & $\begin{array}{c}43.637 \\
(9.314)\end{array}$ & $\begin{array}{c}41.504 \\
(7.988)\end{array}$ \\
\hline$S U P D I R_{01}$ & $\begin{array}{l}1.171 \\
(1.741)\end{array}$ & $\begin{array}{l}1.798 \\
(2.116)\end{array}$ \\
\hline$S U P D I R_{03}$ & $\begin{array}{l}1.333 \\
(1.986)\end{array}$ & $\begin{array}{l}3.362 \\
(3.066)\end{array}$ \\
\hline$S U P I N D_{01}$ & $\begin{array}{l}0.635 \\
(2.643)\end{array}$ & $\begin{array}{l}0.792 \\
(2.932)\end{array}$ \\
\hline$S U P I N D_{03}$ & $\begin{array}{l}0.826 \\
(3.037)\end{array}$ & $\begin{array}{l}2.258 \\
(5.883)\end{array}$ \\
\hline$S A L A R Y_{01}$ & $\begin{array}{l}87964.42 \\
(20974.75)\end{array}$ & $\begin{array}{c}89177.56 \\
(21278.96)\end{array}$ \\
\hline$S A L A R Y_{03}$ & $\begin{array}{c}97536.70 \\
(23414.92)\end{array}$ & $\begin{array}{c}101402.60 \\
(22314.15)\end{array}$ \\
\hline
\end{tabular}

Table 3 contains the means and standard deviations of the key independent variables used in the analysis from the Survey of Doctoral Recipients 2001-2003. See the variable list in Appendix B for variable definitions. 
Table 4: The effect of patent and publication productivity on assignments

\begin{tabular}{|c|c|c|c|c|}
\hline & \multicolumn{4}{|c|}{ Marginal Probability of Becoming Manager } \\
\hline & I & II & III & IV \\
\hline$P A T I N V_{01}$ & $\begin{array}{l}-0.058^{* *} \\
(0.027)\end{array}$ & & & \\
\hline$P A T G R T_{01}$ & & $\begin{array}{l}-0.012^{*} \\
(0.007)\end{array}$ & & \\
\hline$P A T C O M_{01}$ & & & $\begin{array}{l}-0.013 \\
(0.015)\end{array}$ & \\
\hline$P U B L I S H_{01}$ & & & & $\begin{array}{l}0.072 \\
(0.067)\end{array}$ \\
\hline PUBLISH.SCISERV $V_{01}$ & & & & $\begin{array}{l}-0.190^{*} \\
(0.080)\end{array}$ \\
\hline$S A L 10000_{01}$ & $\begin{array}{l}0.027^{* * *} \\
(0.007)\end{array}$ & $\begin{array}{l}0.026^{* * *} \\
(0.007)\end{array}$ & $\begin{array}{l}0.025^{* * *} \\
(0.007)\end{array}$ & $\begin{array}{l}0.026^{*} \\
(0.013)\end{array}$ \\
\hline$S U P D I R_{01}$ & $\begin{array}{l}0.020^{* *} \\
(0.008)\end{array}$ & $\begin{array}{l}0.019^{* *} \\
(0.007)\end{array}$ & $\begin{array}{l}0.019^{* *} \\
(0.008)\end{array}$ & $\begin{array}{l}0.038^{* * *} \\
(0.014)\end{array}$ \\
\hline$M G M T_{01}$ & $\begin{array}{l}0.096^{* * *} \\
(0.031)\end{array}$ & $\begin{array}{l}0.098^{* * *} \\
(0.031)\end{array}$ & $\begin{array}{l}0.094^{* * *} \\
(0.031)\end{array}$ & $\begin{array}{l}0.133^{* *} \\
(0.057)\end{array}$ \\
\hline PREDICTED PROB & 0.256 & 0.256 & 0.256 & 0.247 \\
\hline PSEUDO R2 & 0.109 & 0.108 & 0.106 & 0.178 \\
\hline $\mathrm{N}$ & 1305 & 1305 & 1305 & 397 \\
\hline
\end{tabular}

Significance Levels : $\quad * * *: 1 \%: \quad * *: 5 \% \quad *: 10 \%$

Table 4 presents the marginal probabilities associated with becoming a manager in 2003 from the Survey of Doctoral Recipients 2001-2003. See the variable list in Appendix B for variable definitions. Standard errors are reported in parenthesis. 